\title{
Gearless Power Transmission for Skew Shafts (A SRRS Mechanism)
}

\author{
Amit Kumar ${ }^{1}$ and Mukesh Kumar ${ }^{2}$ \\ ${ }^{1}$ Department of Mechanical Engineering,Baba Saheb Dr. Bheem Rao Ambedkar \\ College of Ag. Engineering \& Technology,etawah U.P. Pin-206001. India, E- \\ ${ }^{2}$ Assistant professor, Department of Mechanical Engineering. G. L. Bajaj Institute \\ of Technology and Management, Greater Noida. (U.P.) Pin-201306 India E-mail \\ ${ }^{1}$ Amit.jnv188@gmail.com, ${ }^{2}$ mukesh.1185@gmail.com
}

\begin{abstract}
Introduced gearless power transmission arrangement used for skew shafts. In this transmission system no. of pins or links used must be odd..3,5,7,9....\& centers of any two pins or links hole must not be on that line which represent the diameter of the shaft. If more pins or links used motion will be smoother, but increase in no. of pins or links not at the cost of strength of the shaft. Pins or links are fixed (may be permanent of temporary) in the drilled holes at the both shaft ends due to which motion is transferred. The dimensions of the pins or links and angle for the pins are all given very precisely, holes drilled very accurately.

Proposed arrangement used for skew shafts at any angle \& if there is a need we can change the angle between shafts during motion or during intermittent motion with any profile of shafts having rotational motion along its own axis. The Working of this arrangement is very smooth \& use very effectively with a very minimum amount of power losses.
\end{abstract}

Keywords: skew shaft, revolute pair, sliding pair, hyperboloids, front/side/top view, intermittent motion

\section{Introduction}

Power transmission for skew shafts is with the help of either crossed helical gear or worm gear or hypoid gears in a machine, but the manufacturing of these gear is very complex, power loss in gears due to sliding motion and the shaft orientations is very limited means not for every shaft orientation because of standardization of gears, so need arises for a better system.

So here I introduced a gearless power transmission system for skew shafts which reduce the losses, cost $\&$ save the time and space. This system allows the changing in the orientation of shafts during motion which is very interesting and fascinating about this mechanism.

Also during analysis of mechanism and working it is seen that this gearless transmission can be used for both intersecting shafts and skew shafts but here we introduced a solution for skew shafts so main attention is towards the skew shafts. 


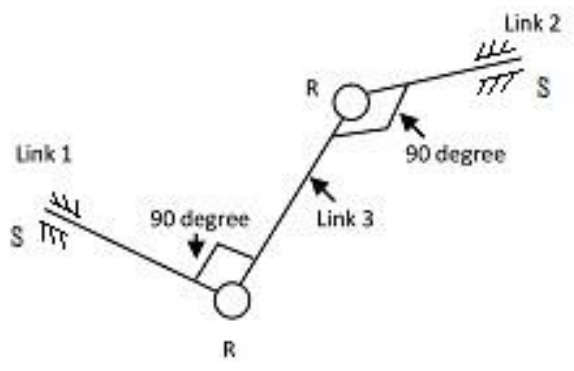

Figure 1.1. SRRS Link in Space

As the name is introduced is SRRS mechanism that is

- $\quad \mathrm{S}$-sliding pair made between link 1 and shaft 1.

- $\mathrm{R}$-revolute pair made between link 1 and link 3 .

- $\quad \mathrm{R}$-revolute pair made between link 3 and link 2 .

- $\quad \mathrm{S}$-sliding pair made between link 2 and shaft 2.

This link further classified as two types [ Type 1 and type 2 ] with different constrained for each.

\section{Literature Review}

1- Skew Shaft :- The term "shaft", used in this standards has a wide meaning and serves for specifications of all outer elements of the part, including those elements, which do not have cylindrical shapes And "skew" means non-parallel and non-intersecting so the shafts which are non-parallel and non-intersecting are known as skew shafts.

2- Crossed helical gears - Helical or "dry fixed" gears offer a refinement over spur gears. The leading edges of the teeth are not parallel to the axis of rotation, but are set at an angle. Since the gear is curved, this angling causes the tooth shape to be a segment of a helix. Helical gears can be meshed in parallel or crossed orientations. The former refers to when the shafts are parallel to each other; this is the most common orientation. In the latter, the shafts are non-parallel, and in this configuration the gears are sometimes known as "skew gears". For a 'crossed' or 'skew' configuration, the gears must have the same pressure angle and normal pitch; however, the helix angle and handedness can be different. The relationship between the two shafts is actually defined by the helix angle(s) of the two shafts and the handedness, as defined:

$E=\beta_{1}+\beta_{2}$ for gears of the same handedness.

$E=\beta_{1}-\beta_{2}$ for gears of opposite handedness.

Where $\beta$ is the helix angle for the gear $\& \mathrm{E}$ is the angle between two shaft. The crossed configuration is less mechanically sound because there is only a point contact between the gears, whereas in the parallel configuration there is a line contact.

3- Worm Gears - A worm drive is a gear arrangement in which a worm (which is a gear in the form of a screw) meshes with a worm gear (which is similar in appearance to a spur gear, and is also called a worm wheel). The terminology is often confused by imprecise use of the term worm gear to refer to the worm, the worm gear, or the worm drive as a unit. [Fig 2.2] 
Like other gear arrangements, a worm drive can reduce rotational speed or allow higher torque to be transmitted.

Worm gears having three types, the first are non-throated worm gears. These don't have a throat, or groove, machined around the circumference of either the worm or worm wheel. The second are single-throated worm gears, in which the worm wheel is throated. The final type are double-throated worm gears, which have both gears throated. This type of gearing can support the highest loading. An enveloping (hourglass) worm has one or more teeth and increases in diameter from its middle portion toward both ends [Figure 2.3].

Double-enveloping worm gearing comprises enveloping worms mated with fully enveloping worm gears. It is also known as globoid worm gearing.

4- Hypoid gears - Hypoid gears resemble spiral bevel gears except the shaft axes do not intersect. The pitch surfaces appear conical but, to compensate for the offset shaft, are in fact hyperboloids of revolution. Hypoid gears are almost always designed to operate with shafts at 90 degrees. [Figure 2.4 ] Depending on which side the shaft is offset to, relative to the angling of the teeth, contact between hypoid gear teeth may be even smoother and more gradual than with spiral bevel gear teeth, but also have a sliding action along the meshing teeth as it rotates and therefore usually require some of the most viscous types of gear oil to avoid it being extruded from the mating tooth faces, the oil is normally designated HP (for hypoid) followed by a number denoting the viscosity. Also, the pinion can be designed with fewer teeth than a spiral bevel pinion, with the result that gear ratios of 60:1 and higher are feasible using a single set of hypoid gears. This style of gear is most common in driving mechanical differentials, which are normally straight cut bevel gears, in motor vehicle axles.

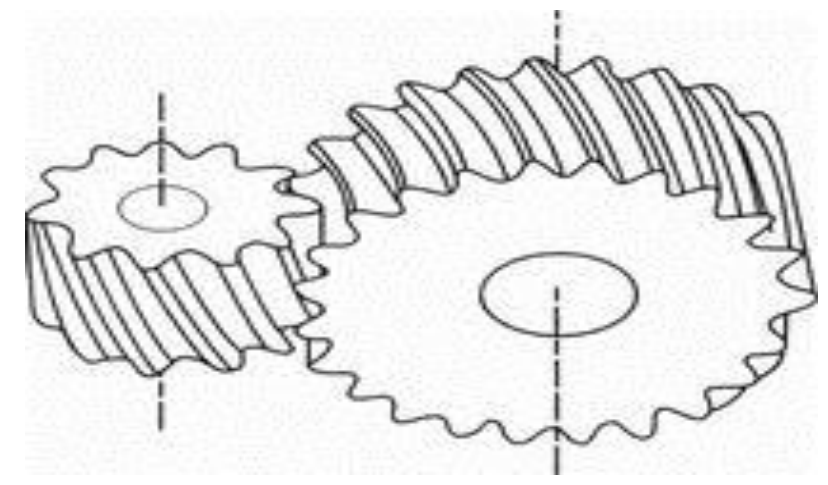

Figure 2.1. Crossed Helical Gears

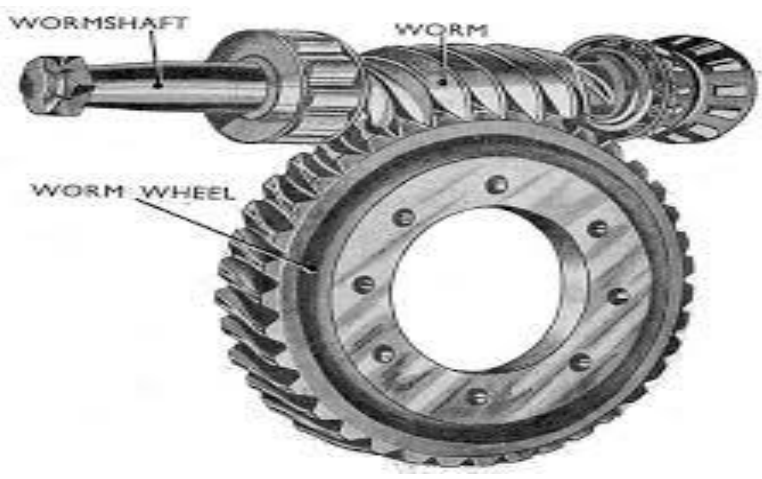

Figure 2.2. Worm Gears 

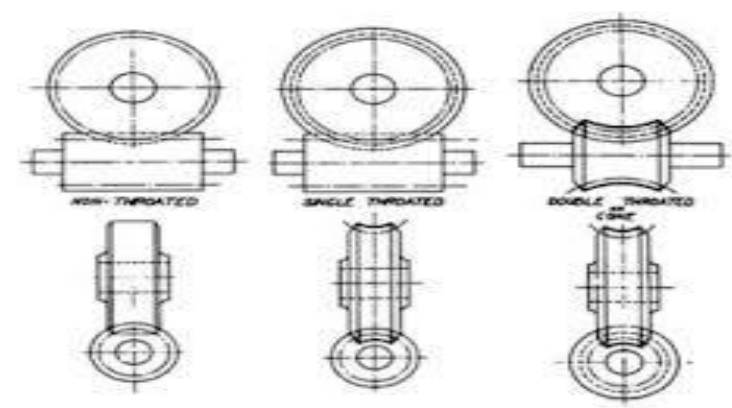

Figure 2.3. Forms of Worm Gears

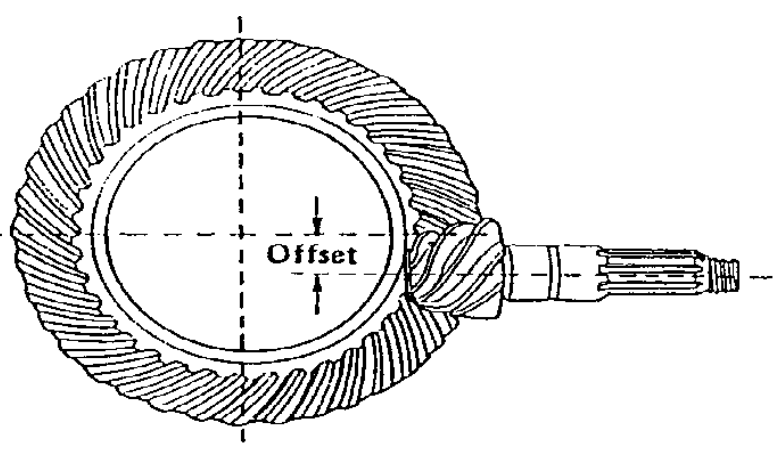

Figure 2.4. Hypoid Gears

\section{Components of the Model and Operation}

In this section different views of the arrangement and the components used for arrangement are shown, which is necessary for understanding the proper working and setup of the arrangement.

A. View of the Planes

Here in the below diagram, planes are shown in the 3D, which helps us in the understanding of the mechanism and movement of shafts and link used.

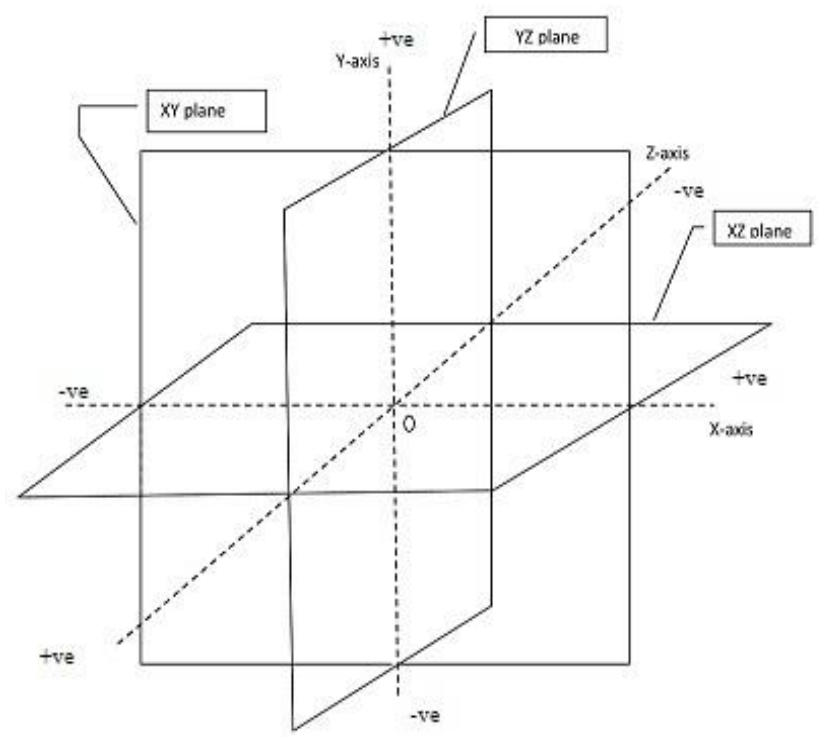

Figure 3.1. View of the Planes 
B. View of the Shafts

Below diagram shows a different view of the shaft arrangement which are skew and angle between them is 90 degrees, which helps us in the understanding of the arrangement of shafts. In below figure (a) front view (b) side view (c) top view.

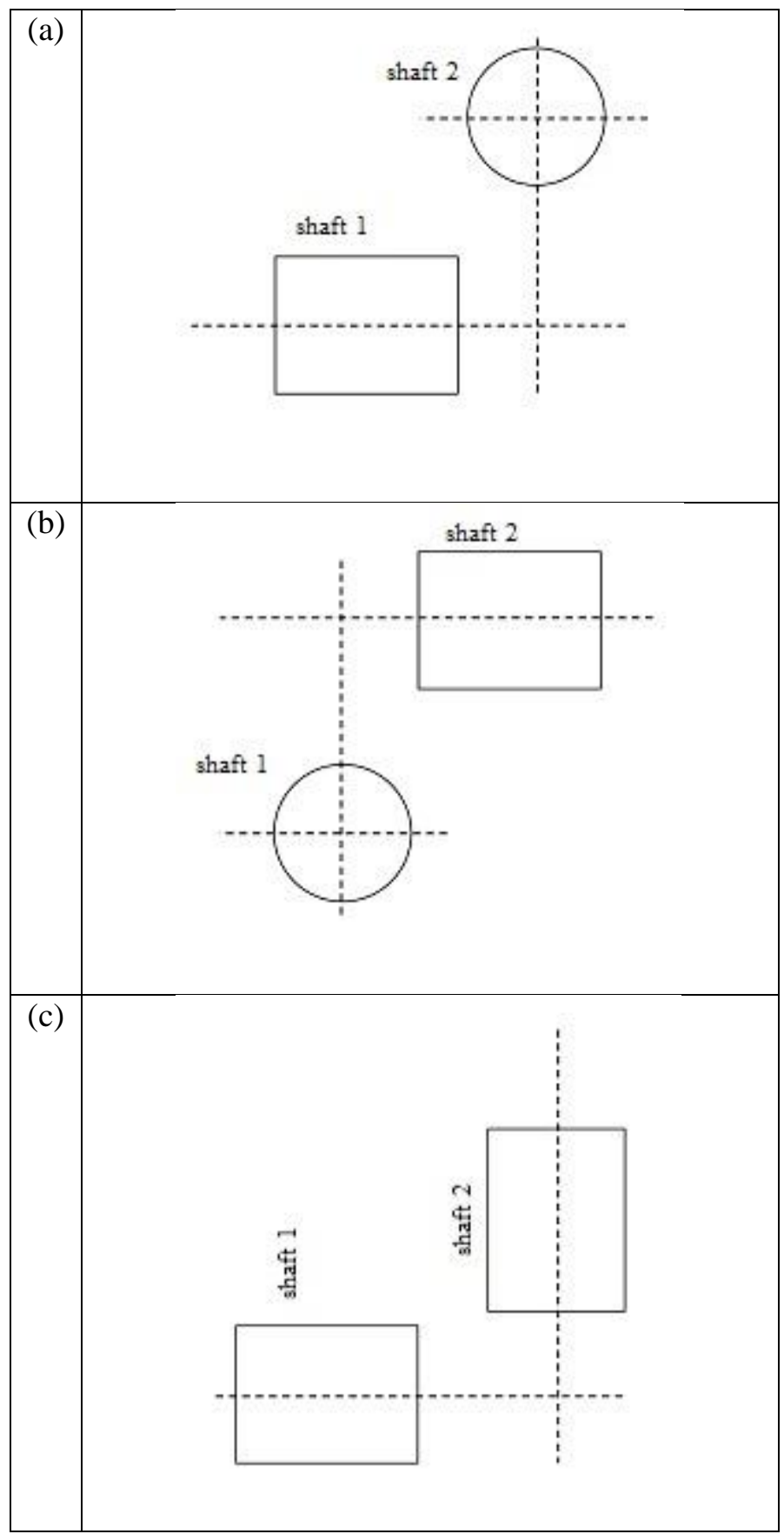

Figure 3.2. View of the Shafts Arrangement

C. Views of Setup

Different views of the setups are shown in Figure (a) Front view. (b) Side view (c) Top view. These views show the arrangement of links and shafts. 


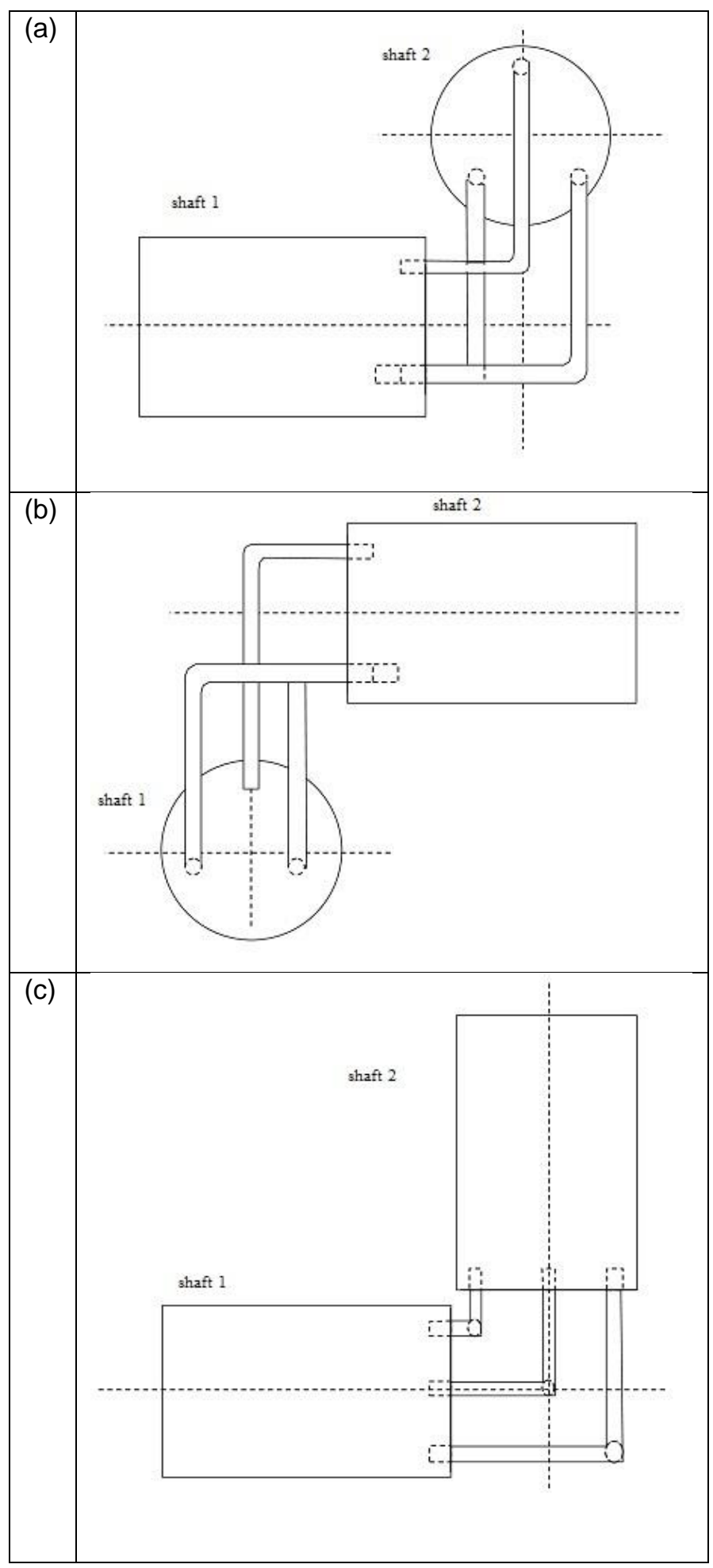

Figure 3.3. Views of the Setup

D. Views of the Pins

Here different views of the pins according to the setup are shown (a) Front view (b) Side view (c) Top view. These pins are used for transmitting the power when there is no change in orientation of shafts during motion. 


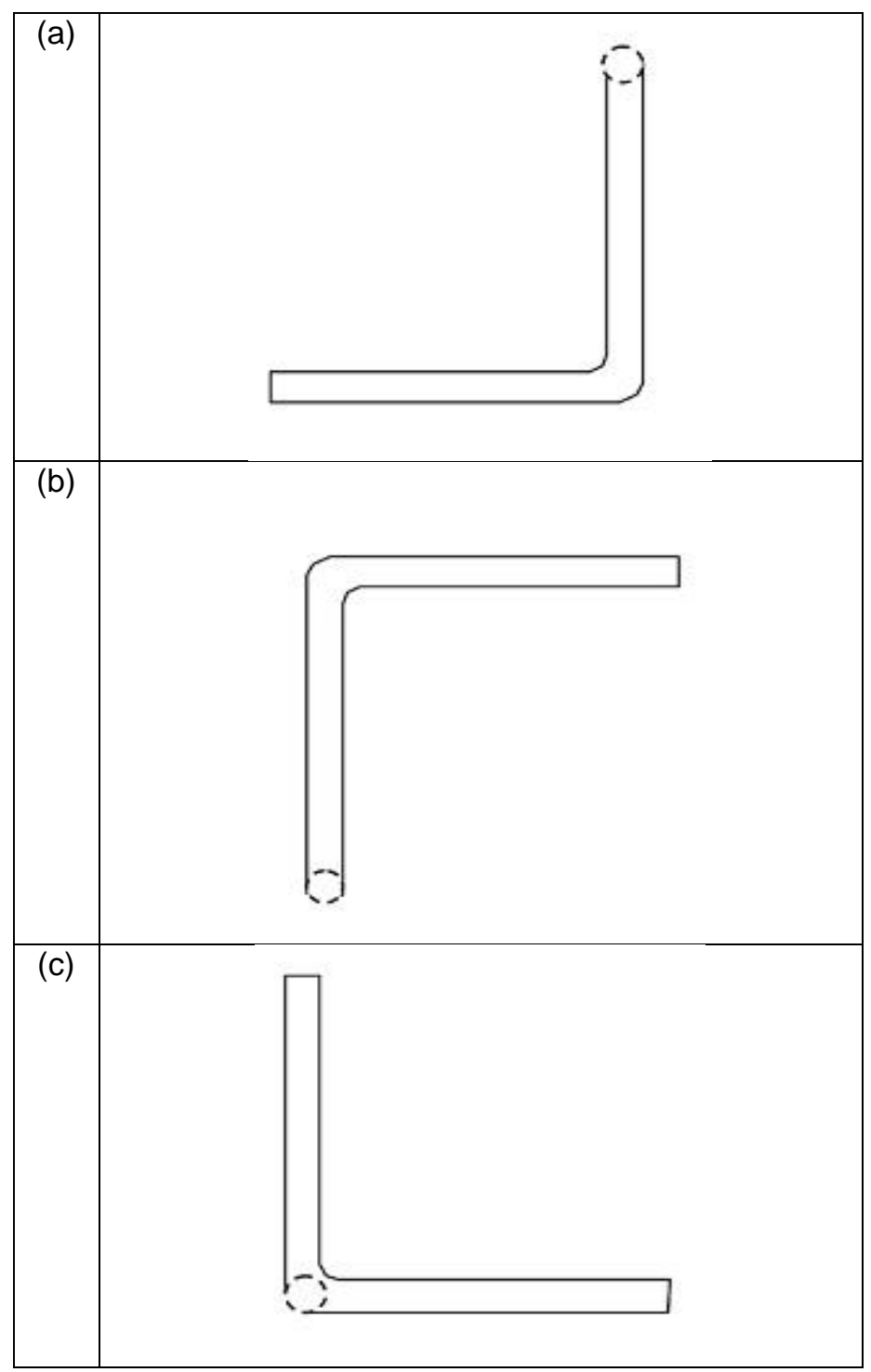

Figure 3.4. View of the Pin

\section{E. Type of SRRS Links Used}

The Links type used for providing the flexibility in motion of skew shafts is shown in Figure 3.5. (a ) SRRS link type 1. (b) SRRS link type 2. Here we introduced the two types of the link, for the ease of understanding of working with different type links. In further discussions we use these types as by the substitution of SRRS from the name of links, so keep in mind link type 1 at the place of SRRS link type 1 \& link type 2 at the place of SRRS link type 2.

Link type 1- In this link having two revolute pairs present and this link permit the constrained movement of both linked shafts in same plane during the motion as need. Link constrained as Let if the link 1 is in $\mathrm{XZ}$ plane along $\mathrm{X}$ axis - link 3 in YZ plane along $\mathrm{Y}$ axis then link 2 in $\mathrm{XZ}$ plane along $\mathrm{Z}$ axis and permit the rotation of link 2 in $\mathrm{XZ}$ plane About $Y$ axis in clockwise direction about 180 degree rotation if viewed from top, such that the initial position of link 2 in XZ plane along -ve axis and after full rotation (180 degree in clockwise direction) final position of link is also in $\mathrm{XZ}$ plane along +ve $\mathrm{Z}$ axis. 
Link type 2- In this link also two revolute pairs present only the difference is that this link permit the constrained movement of shafts in the planes perpendicular to each other. Link constrained as Let if the link 1 is in $\mathrm{XZ}$ plane along $\mathrm{X}$ axis -link 3 in YZ plane along $\mathrm{Y}$ axis then link 2 in $\mathrm{XZ}$ plane along $\mathrm{Z}$ axis and permit the rotation of link 2 in $\mathrm{YZ}$ plane in clockwise direction about $X$ axis with 270 degree rotation if viewed from second quadrant in $\mathrm{YZ}$ plane, such that the initial position of link 2 is between $-\mathrm{ve} \mathrm{Z}$ axis and ve $\mathrm{Y}$ axis (45 degree from both axis) in YZ plane and after full rotation (270 degree in clockwise direction) final position of link is between +ve $\mathrm{Z}$ axis and -ve $\mathrm{Y}$ axis in same plane (45 degree from both axis) . \{ this link permit the more angular movement of link but for efficient power we use upper criteria $\}$

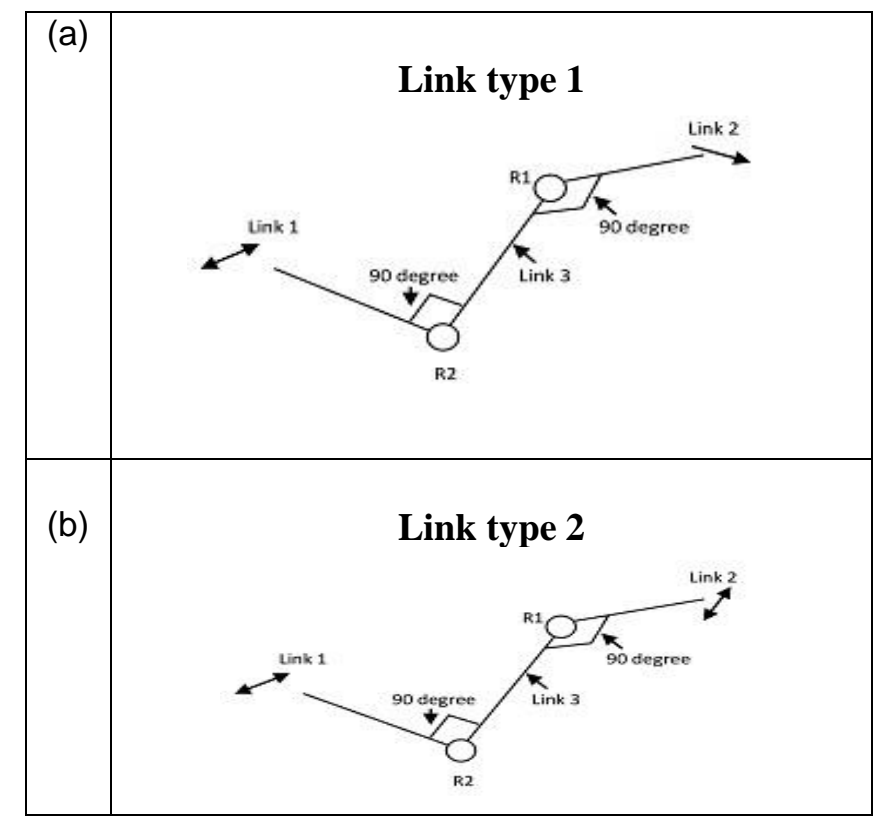

Figure 3.5. Links

\section{F. Arrangement of Pins in Shaft}

In the below diagram for basic arrangement of pins in the shaft holes are shown. The diagram clearly shows that pins used are in odd no.3,5,7,9... and centers of any two pin holes must not be on that line which represent the diameter of the shaft and angle between all consecutive holes should be equal for smoother power transmission. Value of angle such that the its multiple with any integral not equal to 180 degrees.

Let the Value of angle $=\mathrm{x}$ degree

Then $\mathbf{n} * \mathbf{x} \neq \mathbf{1 8 0}$ degree. Where $\mathrm{n}$ is an integral value.

As mentioned, Angle between the centers of any two pin holes must not be on that line which represent the diameter of the shaft because if this happen angle between them is 180 degrees and during motion pins or links use are trying to overlap each other because of this motion interrupted.

Also, as we mentioned that pins no. should be odd and angle between consecutive holes are equal so it can be easily understood by below table that why it is necessary. 


\begin{tabular}{|l|l|l|l|}
\hline $\begin{array}{l}\text { No. of } \\
\text { pins }\end{array}$ & $\begin{array}{l}\text { Angle between } \\
\text { consecutive } \\
\text { hole(degree) }\end{array}$ & $\begin{array}{l}\text { Is value of angle } \\
\text { with any integral } \\
\text { equal to 180 degree }\end{array}$ & $\begin{array}{l}\text { Value of } \\
\text { integral }\end{array}$ \\
\hline 2 (even) & 180 & Yes & 1 \\
\hline 3 (odd) & 120 & No & No integral \\
\hline 4 (even) & 90 & Yes & 2 \\
\hline 5 (odd) & 72 & No & No integral \\
\hline 6 (even) & 60 & Yes & 3 \\
\hline 7 (odd) & 51.43 & No & No integral \\
\hline 8 (even) & 45 & Yes & 4 \\
\hline 9 (odd) & 40 & No & No integral \\
\hline
\end{tabular}

In upper table it is seen that with any no. of pins other than odd there must be an integral whose multiplication with angle gives the value 180 degrees so only odd no. of pins used.

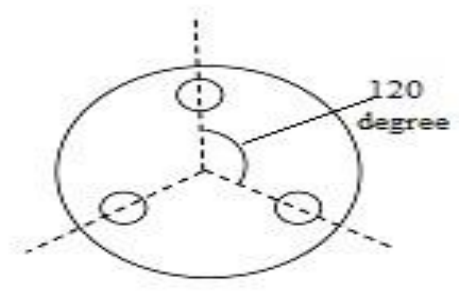

Figure 3.6. View of Shaft with Holes

G. Analysis of Mechanism

From the above diagram's and views the setup is clearly established in the mind, but as for convenience here we use the front view of the setup for analysing the mechanism of setup.

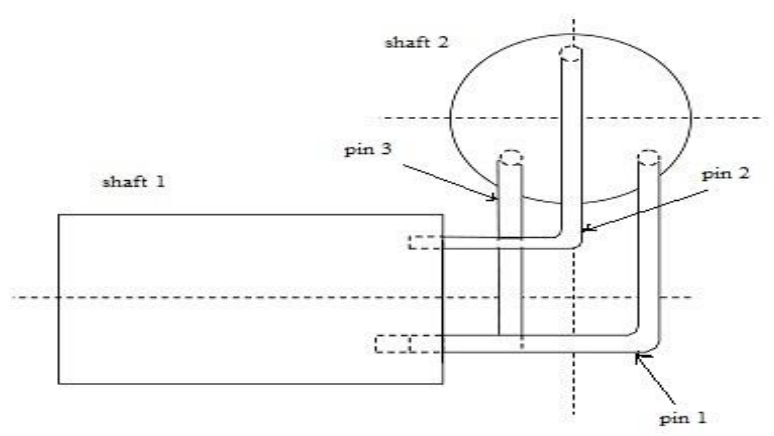

Figure 3.7. Setup

Let at the starting instant shaft 1 starts rotation with 3 pins in anticlockwise direction and a reaction force developed at the pin surface which in contact with the shaft and this force transferred to the other end of the pin which is in the shaft and applying on the shaft 2 due to which shaft 2 starts rotating in the same direction as shaft 1, after 120 degree rotation pin 1 comes at the place of pin $2 \&$ pin 2 comes at the place of pin $3 \&$ pin 3 comes at the place of pin 1 by sliding in shaft and self adjusting. This motion repeated for next 120 degrees and further for next 120 degrees and pins are exchanging the position in successive order as discussed before. 


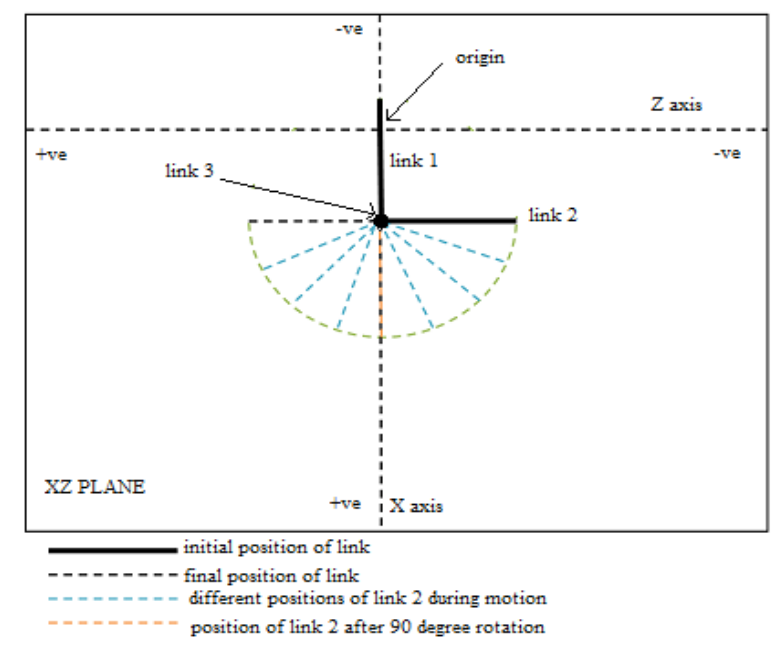

Figure 3.8. Movement of Link 2 of Link Type 1 in XZ Plane

Working with pins - pins are used with the arrangement when there is no need of change in positions of pins during motion and very high speed required.

Working with links- links are used in the arrangement at the place of pins if we required flexible motion or orientation on pins are changes during motion or during intermittent motion.

I. Working with link type 1 permits that during motion shaft 2 can move in the plane $\mathrm{XZ}$ from initial position to final position (initial and final position is indicated in section E and also in upper Figure 3.8 )

II. Working with link type 2 permits that during motion shaft 2 can move in the plane YZ from the initial position to final position as indicated in section $E$ and also in below Figure 3.9.

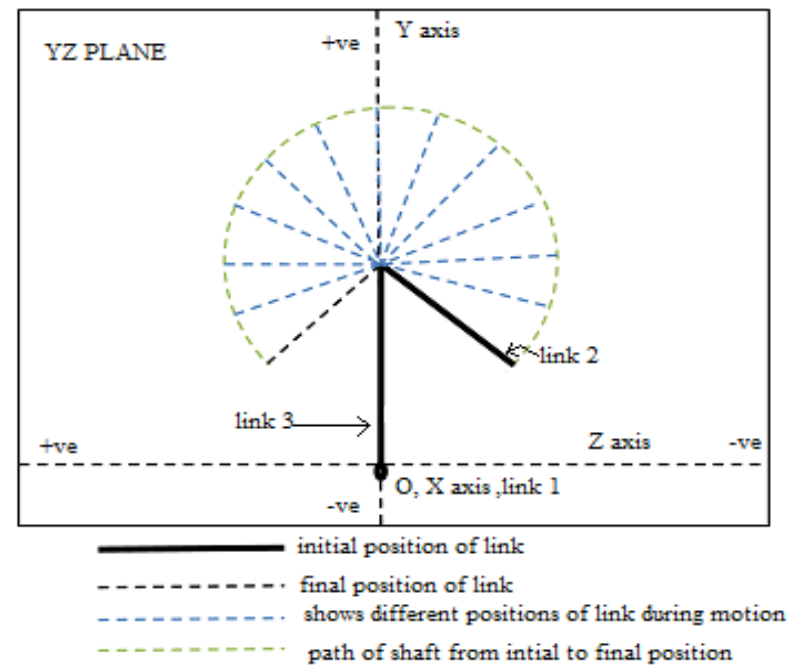

Figure 3.9. Movement of Link 2 of Link Type 2 in YZ Plane

More arrangement can be possible for the shafts with such type of links which can be easily understandable during working.

Some intermittent positions during working which are well known and shows that 


\section{introduced setup is working well-}

- Working with link type 1-

$\Rightarrow$ During motion initial position is skew shafts at 90 degrees and this arrangement is similar to working with pins as discussed previous so first position is working.

$\Rightarrow$ After 90 degrees rotation of link 2 of link type 1 system is transformed as gearless transmission for offset shaft and it is well established arrangement for pins, which can be seen with the help of reference [2], so this position is also working.

$\Rightarrow$ After 180 degrees rotation shafts again in position as first so this position is also working.

From above intermittent positions it is easy to understand that system with link 1 is working well.

- Working with link type 2-

$\Rightarrow$ First position is easy to understand with setup and also by imagination as similar to working with pins.

$\Rightarrow$ Second position, After 45 degrees rotation of link 2 position is similar to the initial position of for working with link type 1 , so this position is working well.

$\Rightarrow$ After 135 degrees rotation setup is changed as gearless power transmission for intersecting shafts at 90 degree which is used in elbow engine with pins and can be easily understand with the help of reference [3], so this position is also working well.

$\Rightarrow$ After 225 degrees and 270 degrees rotation positions of setup is similar to first and second position so these positions also working well.

Hence working with both type of link is well and correct.

\section{Comparision with Existing Solutions}

1- This arrangement gives the coverage of a wide range of shaft diameter, which may be standard or non standard which is not possible in the existing gear arrangement because the manufacturing of gears for skew shafts very complex and because of standardization its only use of shafts of standard diameter.

2- Proposed gear less transmission with pins can be used for very high speeds and for high loads which is comparable to the worm gear and not possible for crossed helical gears.

3- This system not having any possibility of like sliding and point contact as in crossed helical gears so power loss is very low in introduced arrangement and used for high loads with proper rigidity of shafts and pins.

4- The main and very interesting advantage of this proposed system is that we can changes the position of shafts during motion or during intermittent position according to need by using given type of links at the place of pins which is not possible in any existing system till now.

5- Since any dimension of any component used is not out the shafts dimensions limit, a large reduction in the size of the machines is possible in short a large space saving should be done.

6- Repairing cost on failure of any component is very low.

7- Very low setup cost.

8- Easy and time saving installation of setup.

9- Easy manufacturing of links and pins in comparison of crossed helical and worm gear.

10- Very less skill is required for setup. 
11- Proposed arrangement can be used for shaft of any profile but shafts must be having rotational motion about its axis.

\section{Applications}

Applications areas of skew shafts is very less because of the complexities entailed in their manufacture and in installation of setup so the propose gearless transmission is very efficient and good for the use of skew shafts. As in the introduced arrangement we can change the orientations of shafts during motion or by intermittent motion, new possibilities in transmission design opened up. Also where the space availability is less and crossed helical gears or any other appliance cannot be used, this arrangement can employed very easily and effectively with very less amount of power loss.

\section{Conclusions}

During working on experimental setup and after a long discussion it is observed that proposed arrangement used for any set of diameters with any profile of shafts for skew shafts of any angle but the shaft's must be having the rotational motion about his own axis, transmission of motion is very smooth and desirable and used only for the equal R.P.M. of driving shaft and driven shaft by employing pins or given type of links for appropriate joints for revolute pair.

\section{References}

[1] Book s. s. rattan Mc Graw Hill Education ( India ) private limited, new delhi.

[2] A. Kumar and S. Das, "An arrangement for power transmission between co-axial shafts of different diameter", International journal of engineering research and technology, ISSN:2278-0181, vol. 4, (2015) January.

[3] ,Mahantesh Tanodi1, S. B. Yapalaparvi2, Anand. C. Mattikalli3, D. N. Inamdar2, G. V. Chiniwalar2,1, PG Scholar, Department of Mechanical Engineering, Maratha Mandal Engineering College Belgaum, Karnataka, India, 2Asst.Professor, Department of Mechanical Engineering, Hirasugar Institute of Technology Nidasoshi, Karnataka, India, 3Asst.Professor, PG Coordinator, Department of Mechanical Engineering, Maratha Mandal Engineering College Belgaum, Karnataka, India, "Gear less power transmission: parallel offset shaft coupling", Journal:- IJERT

[4] https://www.youtube.com/watch? $\mathrm{v}=$ Que1Uhsk4wE or Navneet Bardiya1, karthik.T2, L Bhaskara Rao3 School of Mechanical and Building Sciences VIT University Chennai campus, Chennai, India Email: navneet.bardiya2013@vit.ac.in1,karthik.t2013@vit.ac.in2,bhaskararao@vit.ac.in3 journal :- IJCEM.

\section{Authors}

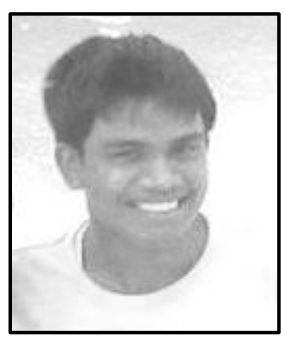

Amit Kumar, $12^{\text {th }}$ pass out from jawahar navodaya vidyalaya bareilly (u.p.) and now Pursuing bachelor of technology in dicipline of mechanical engineering from Baba Saheb Dr. bheem rao ambedkar College of Ag. Engineering \& Technology, etawah U.P. Affilation:- C.S.A. univ. of Ag. And tech. kanpur, Pin-206001. India, E-mail- Amit.jnv188@gmail.com.

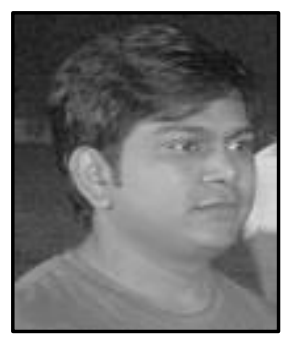

Mukesh Kumar, B.tech in mechanical engineering from V.I.E.T. GZB and M.tech from I.I.T BHU currently working as a assistant professor in G. L. Bajaj Institute of Technology and Management, Greater Noida. (U.P.) Pin-201306, India. 